\title{
A mother's experience of her child's time in intensive care: Part 1
}

\author{
Kate Macdonald, PhD, Editor, Institute of Health and Community Studies, Bournemouth University, \\ Bournemouth, UK (ब) \\ Jos Latour, RN, MScN, Nurse Manager, PICU, University Hospital, Vrije Universiteit, Amsterdam, \\ The Netherlands \\ Karin Storm, MSc, Clinical Nurse Specialist, ICU, National University Hospital, Copenhagen, Denmark
}

Kate Macdonald, Institute of Health and Community Studies, Bournemouth University, Royal London House, Christchurch Road,

Bournemouth BH1 3LT. e-mail: kmacdona@bournemouth.ac.uk

\section{KARIN STORM INTRODUCES THIS TWO-PART ACCOUNT:}

In the first part of her story, Kate Macdonald describes in detail what happened when her daughter Mary was admitted to her local hospital with whooping cough and pneumonia. In part two (to be published in the next issue of Connect) she recalls the events when, later, Mary was transferred to the regional paediatric intensive care unit (PICU).

Mary became increasingly ill during her time in hospital and Kate was dealing with the worst situation a mother can imagine. She offers a vivid description of a mother's reactions to her infant's illness, recalling her own thoughts at different stages during the hospital admission. She says that initially she was not aware of the seriousness of her daughter's condition. For example, in the beginning, she focused on minute-by-minute events such as feeding, and was incapable of seeing the whole picture i.e. that her child was seriously ill in hospital, in an isolation room, requiring oxygen therapy and constant attention.

Later, when Mary needed to be transferred to the intensive care unit (ICU), Kate began to realise that her child's life was out of her control. In addition to coping with this critical event she and her husband had to make arrangements for their other children, Lucy and Holly. It was a problem to let the children visit the unit because she and her husband needed to be with Mary all the time. During all of this, Kate was aware of how the staff were acting, reacting and interacting and she often comments on this.

Kate Macdonald's article is very touching and very relevant for nurses who care for the parents of critically ill infants. There is much that nurses can learn from Kate's experience.

\section{KATE MACDONALD CONTINUES:}

My youngest daughter Mary was eight weeks old. She had had a cough for three weeks. After the third visit to our family doctor she was admitted to hospital.

\section{Admission}

In the children's admissions ward we were taken to a separate room in case Mary was infectious, and swabs were taken from her nose. The registrar diagnosed whooping cough straight away, which amazed me: I had only ever heard about whooping cough when arranging for vaccinations for my other daughters, and I had no idea what it was like. The doctor also said that she might have pneumonia, which alarmed me more, as I had had it myself a year before, and remembered the painful struggle to breathe before the antibiotics began to work.

Mary was given an oxygen monitor to wear strapped to her foot, and this immediately showed that her oxygen saturation levels ('sats') were rather low, at 80 . She was given a little oxygen mask for us to hold in front of her face, which kept the levels up fairly successfully; the mask did not seem to bother her too much at first. The 'sats' machine alarm was set to go off when the level fell to 92, and the next two hours were spent by David (my husband) and me taking turns to hold Mary on our laps, while she slept or looked around, or fed from me, all the time keeping the oxygen mask near her face.

Mary was X-rayed. I had some of my sandwiches. We kept repeating the list of symptoms and history of her illness to the different nurses and doctors who examined her, and we displayed the last of the steroid tablets that Mary had been taking, again and again.

\section{On the children's ward}

David went home and Mary and I were bedded down in an isolation room in the children's ward for the night. I slept on the sofa, and she was given a head box for her oxygen. She seemed puzzled by this, but slept very well in her nappy, waking up occasionally to look about at the starfish pictures on the wall and ceiling. I had put her soft brown toy rabbit on the box so she could see it: it also shielded her eyes from the lights above.

She had a drip put into her hand to increase her fluid intake; although she had had a couple of feeds during the evening she had not taken in enough fluid at either. At the time I was so pleased to have been able her to feed her at all that I disregarded the difference in volume. I slept, on and off, waking to deal with her coughs. The alarm bleeped madly when her 'sats' went below 92, which happened again and again. On one occasion, because I was half awake most of the time, I had untangled myself from the sheets, had hit the emergency buzzer, got the cot 
side down and was getting Mary out of her head box and fitting the oxygen tube onto a face mask for her before the nurse arrived. The ward sister was very encouraging about my doing this, and I felt good too, being able to help with Mary's nursing.

\section{I could not 'see the whole picture'}

Now, I can see that I was so focused on the minute-by-minute events, the slight advances and setbacks in Mary's condition, and watching the numbers on the machine, that I was incapable of seeing or comprehending the whole picture: that Mary was in hospital, in an isolation room, needing oxygen and constant attendance. Exhaustion and tension was beginning to have an effect on my judgment. I was dimly aware of a midnight visit from nurses and doctors, but assumed that this was just part of the usual rounds. We tried another feed at 6 o'clock in the morning, but by then Mary did not want it. She cried and turned her face away.

I left Mary asleep, with the nurses within earshot, and had breakfast in the staff canteen. I telephoned David at home to report on the night. He was dealing with Lucy's nappy at the time, which made life seem quite normal again. I also called my mother to tell her we were in hospital. I remember trying to be calm. I did not want to alarm her - but I exaggerated my calmness, remarking that Mary being in hospital was 'a bit of a bore'. My mother, being understandably anxious at the news, retorted that it wasn't a bore, that it was terrible. Then naturally I burst into tears, which probably alarmed her even more.

When I got back to Mary's room the nurses had put her gastric nasal tube in, without fuss from her, and she accepted a bottle of milk without bringing it back up, which pleased the nurses very much. The milk I managed to express was fed to Mary through the nasal tube a little later, but she vomited it back with the next coughing fit.

Our nanny, Sam, brought Lucy to visit us while Holly was at school, but I could not concentrate, especially while Mary was coughing again. I read Lucy a story, and held her up so she could hold Mary's hand, then they went home. Sam had brought my laptop computer with her as I had work to finish for a deadline, but I had already realised that I would not be able to do any work. Reality had shrunk into Mary's cot and our little room, and anything happening outside that had no relevance. I tried to read the newspaper that Sam had brought, but gave up. I spent half an hour organising the part-finished book I was editing, for David to send back to the publisher that night, and rang some colleagues to redirect the job. I found myself having to listen to stories of other people's children going through whooping cough, but I was impatient to get back to Mary.

Another nurse had come on duty to help Mary's day nurse. She quietly got on with her work, checking Mary's readings, her oxygen and the IV progress, and she started to write notes. I slowly realised that Mary was getting one-to-one care. This new nurse never left our room unless I was there and watching, and even then only for a few minutes to fetch more equipment or to ask the ward sister to get something arranged. I had no experience of hospital procedures, other than in maternity wards. I had never even seen a hospital drama series on the TV, so I did not make any connection between the intensified nursing and the gravity of Mary's illness. The focusing of my attention on the machine readings and whether she was taking food was still making me incapable of seeing what was really happening. Mary slept on, waking with her coughing spasms but mostly going to sleep after they were over.

\section{The beginning of reality}

The consultant did his morning rounds. When he came back to
Mary's room the nurses stood around me as I was standing by Mary's cot, like a protective blanket. Then the consultant told me that it was very likely that Mary had whooping cough, complicated by pneumonia, and that she might have to go into intensive care. She could not go to this hospital's neonatal intensive care ward as there were no beds free - she would have to go to the regional centre 20 miles away. I started to cry. It was a huge change to admit to myself, and such a horrible feeling, that Mary's life was out of my control. I asked how long she would have to be in intensive care and the consultant said it would be a few days. This felt better. Knowing what we know now, it was horribly misleading.

David arrived with the girls an hour later. By this time Mary's oxygen mask and head box were not working for her as well as before, and her 'sats' were slipping more and more. Both nurses were in and out of the room, the ward sister coming in to check on things frequently. A continual and growing hum of activity was punctuated by Mary's choking purple-faced coughs. David and I took turns keeping an eye on Holly and Lucy, and helping one of the nurses with Mary. Holly and Lucy were not too affected by Mary's struggles, as they were excited about the toys in the children's ward, and I made myself take walks with them up and down the corridors, examining the artwork on the walls and dangling from the ceilings. They played vigorously with the giant teddies and stuffed toys, the dilapidated cars and push-along toys.

Focusing on my two other children was a conscious wrench away, as well as a physical turning away of my head, from constantly thinking about Mary. I found it very hard being away from her room and cot, even while David was with her, only just down the corridor. While it was my turn to watch Holly and Lucy I could not risk getting too involved with what was going on with Mary in case the two older girls escaped into some other rooms, or out of the ward completely. I acted on 'auto-pilot', or by consciously switching off my awareness to the activities in Mary's room. I was existing in two parallel worlds: trying to keep calm and cheerful while being Holly and Lucy's normal mother, and at the same time trying to overhear what the nurse and the doctors were saying about Mary; in case they were telling David something new. At one point I was sitting on the sofa playing snakes and ladders, Lucy perpetually running off with the dice, while in the same room David and the nurses were struggling to give Mary the oxygen she needed and to support her through a hacking, purple-faced spasm.

It had become obvious to me that David and I now needed to be with Mary all the time. I rang Sam to ask her to collect Holly and Lucy and stay with them at home that evening until we could find someone to relieve her. David had rung his mother in Devon, two-and-a-half hours' drive away, to get her to take over child care for the weekend. Both women came as fast as they could, but we could not give them any choice: we needed help badly and we needed people Holly and Lucy knew.

All this time we were waiting for the team from the regional PICU to arrive and take over Mary's care. One of the doctors had refused to put a second IV drip in Mary's other hand, in preparation for PICU's arrival, because he was going off duty. This was the first and only instance of less than professional behaviour from all the medical staff we encountered. It made me angry for the first time - but I was also able to consider that he could have been on call overnight and into the afternoon. It was a temporary rage, born of panic. I was starting to get demanding, but all I could do was keep insisting that Mary had the second line put into her hand. This would do no good until the new intensive care team arrived - but it had assumed the importance of a solution to the crisis. 


\section{Relinquishing the helping role}

The simple nursing tasks that David and I had been managing fairly well on our own were becoming less necessary, and there were now more machines involved. Relinquishing this supporting role was a relief in a way: as we could not help, we had to concentrate properly on Holly and Lucy, keeping our minds distracted from Mary. Our baby was beginning to vanish from sight as more people came in and out of her room, standing round the cot while they did things to the machines and to help her.

My last memory of Mary awake is of supporting her through a cough, stroking and patting her back and holding the oxygen mask near her nose, while her big eyes were fixed on mine, her face all mottled patches of purplish-red as she struggled for breath. She was really looking at me then. Up until then, for the whole of her short life, she had hardly ever focused properly on anyone, her gaze shifting over our shoulders or away into a middle distance. It's a sad memory, the last time we looked at each other and saw each other properly, but it was also a moment of communication which we had not had before.

\section{Transfer to the adult ICU}

The intensive care team from our own hospital arrived at about 5 o'clock that evening, summoned by Mary's consultant because the team from the PICU still could not get an ambulance to bring them. The doctors, anaesthetists and nurses were very affable, chatting to each other, and to us and the girls, over and around Mary's cot, as they prepared her to be moved upstairs to the ICU. The two intensive care teams were consulting with each other by telephone about Mary's ventilation throughout this period, so no care was compromised or time lost. At this point Mary's brown rabbit disappeared. Holly and Lucy had been running more or less wildly up and down the ward corridors, and I think Lucy must have dashed off with Mary's rabbit and left it somewhere. We never saw it again.

Intensive care staff wheeled Mary away in her cot, with her drips and machines, and David and I struggled to stay calm and sort out our belongings. We had to separate mine and Mary's clothes from the other stuff that had accumulated, and make sure that Sam took my laptop as it would be safer at home than in our car. David took a load of things to the car, ready for driving to PICU. I was left with Holly and Lucy. The little room was very empty without all Mary's paraphernalia. Also, there was no longer the constraint of other people or the flurry of activity to mask what I might be feeling, or how I might be looking or sounding to the girls.

David went upstairs to the ICU straight away, while I stayed with Holly and Lucy. I knew that I might not see them for a day or two, and I had not seen them properly for that day anyway. It was very hard to give them proper attention and not be distracted by thoughts of what was being done to Mary upstairs, but I did it because I had to. We played board games with pieces missing, and read stories with half a mind elsewhere, but while I was in the toilet they escaped! I found them fairly quickly, perched on a spare bed in a corridor around the corner, snuggled up to a gigantic teddy. I gave them a cuddle and we stood waiting for Sam to arrive. When she arrived she distracted Holly and Lucy with questions about what they wanted for tea (they were very hungry), and so we put on their coats and loaded up the buggy. Once they were gone I drank two large glasses of water, suddenly so thirsty, trying to calm myself for the next stage. Holly and Lucy were no longer our immediate responsibility as Sam and Eileen had taken over: we could give all our thoughts to Mary.

\section{In the ICU}

Upstairs, I found David in a waiting room, looking at the newspaper, sitting opposite the family of an elderly man and two women looking blank and tense. They were called into the ward shortly afterwards, but we had to wait for about an hour. David had some coffee and we both looked through the magazines and the remains of our newspaper. Every time there was movement in the corridors we expected it to be someone coming to collect us: the wait seemed endless. We had felt reassured by the friendly, calm professionalism of the team who collected Mary and took her away, and this newly carpeted and decorated nest of corridors was also a reassurance. The children's ward had been mildly chaotic, visitors and parents and children everywhere; this was a serious but comfortable place.

When we were able to see Mary she was sedated and stuffed with tubes. The ward sister had come to see us beforehand and had told us exactly what had been done, so we knew what to expect. I have no problem with the tubes and bleeping machines that signify hospital care, and it was a relief to see her lying so quietly and peacefully, though tucked between two sheets of plastic bubble-wrap for insulation. Her head was turned away to the window slightly, supported by a rolled-up towel, and she was breathing easily and regularly through the ventilator, a tube coming out of her mouth to match all the other tubes snaking in different directions from her body and out of sight under her covers and the bed. We sat with her all evening, more or less, as the PICU ambulance took forever to arrive.

The intensive care nurses were in another uniform, more like what I would have expected in an operating theatre, easily washable and scrubbable, not like the everyday staff sweatshirts and polo shirts of the children's ward nurses. The senior staff on duty talked to us about Mary and what they had done, and what antibiotics and fluids she was being given, but I had reached saturation point: I could not really ask or say anything with meaning, only think about practical arrangements. I was struck by how human and normal and friendly they were, although why I would have expected anything other than that I do not know. The children's ward consultant had been distant and formal, but these women were people whom I might have known through work or family, and treated me like someone they knew, not a stranger or a tiresome distraught parent. David found himself fuming at the consultants' clothes, quite ordinary but welldressed, 'as if they were going to a party', but I felt reassured again. The way they looked took the clinical metal-edged coldness of Mary's ward away.

\section{The realisation that Mary might die}

It is interesting that it had taken me all afternoon to realise that Mary might die. On Friday morning I was still asking doctors and nurses how long it would take her to recuperate, but I never received a definite answer, only vague replies which I couldn't understand or relay properly to David. I thought at the time it must have been me not hearing properly or misunderstanding, but I now see that I was getting no certain replies because the medical staff knew that there would be no recuperation, or very little chance of it. The consultant in the children's ward had at first said that he would wait until Saturday morning before deciding on intensive care or not. A couple of hours later he was saying 'mid-afternoon'. In the end, they brought in their own intensive care team by 5 o'clock, without waiting any longer for the PICU team to arrive. It was only once Mary had been taken upstairs to intensive care, and we had relinquished Holly and Lucy's care, that it sank in with me that this was really serious. It felt believable, finally - it was really happening. 
I ate a tasteless sandwich and had a drink of water; talked to my mother-in-law, now at our house with the girls fast asleep; and went back to sit with David by Mary's bed. She was tiny, a morsel lying on this huge adult bed, which left a lot of room for all the equipment and notes. The nurses were very friendly and accessible, and various doctors and anaesthetists wandered in and out, checking up on her, or showing interest.

The consultant anaesthetist showed us new X-rays of Mary's lungs, which meant nothing to me. They should have been black, but the tubes and alveoli were partly filled up with cloudy white. One of the anaesthetists looked familiar, and I remembered that she had assisted in Mary's delivery, eight weeks before. She remembered us too, and asked us, joking, if we were having any more children. I wonder now if she knew that Mary was unlikely to survive.

I went back down to the children's ward to express milk again, in case Mary could use it. I was trying to use my time, to do jobs when I could, in case I had no time in the future. David sat with Mary all the time. I seemed to be continually wandering off to do different things.

While looking at the X-rays in the intensive care ward we could not help but see the other bodies lying in their cubicles, women and men naked except for bandages and electrodes: partially uncovered, breathing noisily, surrounded by machines. They were like a city of wounded giants compared to our little Mary - tiny Mary in her bubble-wrap and duckling duvet cover. Her hands and feet were cold, so her nurse found a little pink knitted bonnet for her. Wearing this bonnet with the strings tied under her chin, a bow at the side, Mary looked unpleasantly like photographs I had seen of exhumed (but intact) infant victims of smallpox; I had edited a book on post-medieval archaeology several years before. I remember thinking that this was an unlucky thought. The nurse also found a warm air-blower and managed to get Mary's feet a little warmer by blowing the air into her bubble-wrap. The ward was air-conditioned and very chilly.

At around 11.45 that evening we were told that there would still be at least an hour before the PICU ambulance arrived and that it would take half an hour then to get Mary transferred to the ambulance. We needed to sleep, so we were shown to a hoteltype room with two beds, across the corridor from Mary's ward; we slept for two hours. The PICU ambulance still had not arrived when we rushed back to the ward.

Eventually the ambulance arrived at 1.30 in the morning, the team swarming into Mary's cubicle with their equipment in a business-like manner. Suddenly it was a busy place again. We got out of their way, and left the hospital to get our car. The ambulance's arrival had made us a little more relaxed. We felt as if things were beginning to happen, and Mary was out of stasis and in a moving stream of activity again.

\section{JOS LATOUR PROVIDES A SUMMARY OF THE STORY FROM THE NURSING POINT OF VIEW:}

In this real life story, Kate Macdonald tells of the admission of her daughter Mary to the paediatric ward and later on to the adult ICU. For Kate, unfortunately, a once in a lifetime experience; but for paediatric and intensive care nurses it is more or less daily practice. Nursing care of a critically ill child is not only about the knowledge, understanding and intervention relating to pathophysiological changes that can occur, but also the understanding of parental stress and their coping mechanisms.

Admission of a child to hospital is, in most cases, unexpec- ted, and always has dramatic effects on parents, especially when it comes to an intensive care admission. The influence of changes in the health of their child, the working commitments of the parents, and the situation at home with other children are factors that affect their coping strategies.

In the past two decades the stresses of coping for parents with a critically ill child have been studied extensively. In the late 1980s, Miles and Carter (Miles et al., 1989; Carter and Miles, 1989) developed a Parental Stressor Scale, which assesses seven dimensions of stress experienced by parents in the PICU. Based on stress theory, it identifies potential sources of stress. The framework suggests that personal, situational and ICU environmental stress stimuli interactively impact on the parents' overall stress response. This tool has been widely used in research, and can be helpful when assessing parental coping. The dimensions are related to the child's behaviour, alteration in parental role, staff behaviour, staff communication, PICU sights and sounds, invasive procedures, and the child's appearance.

Kate Macdonald describes in detail how her child Mary reacts to her illness. Kate's role then changed from being a mother to being a mother and a primary caregiver. At this moment, guidance from the nurses for the parents is of great importance. It will help parents in their coping process during and after the hospital admission. The behaviour of the nursing and medical staff should be empathetic in every situation. An arm around Kate's shoulder, when she heard from the consultant that Mary would be transferred to a PICU 20 miles away, would have expressed sympathy and probably been the best thing for her at that moment.

Until the transfer to the PICU, some communication uncertainty seemed to occur in the information given to Kate, before giving a nasal gastric tube to Mary, up to the situation before Mary's transfer to the adult ICU. Communication, for example, informing the parents especially before or during invasive interventions, is important to reduce stress levels. As Kate stated, 'the wait seemed endless' before she and her husband could visit Mary in the ICU. This shows how important it is to inform parents as soon as possible. Some questions arise. For example: why did they have to wait and for what did they have to wait? There may have been good reasons, but they do not appear to have been explained to Kate and her husband. Most people would agree that it is better to know the truth, so that coping can occur. Often what may be the relatives' imagined scenario, is far worse than the reality. Many healthcare professionals argue that it is the right of the parents to be with their children during all procedures, no matter how invasive they are. Further professional discussion, and research, which examines parental presence from their perspective will help to guide our practice in the future.

Knowledge of ways of coping with stress is essential in nursing practice in order to detect coping mechanisms and provide individual care. The first part of Kate's story reinforces for us, that nursing care is not only about providing the best care to the child but also providing care for the 'psychologically critically ill' parents.

And Mary's brown rabbit ... we will never see it again. The rabbit was part of Mary's life and so should have been very much a part of the family-centred care.

\section{REFERENCES}

Carter MC, Miles MS. (1989). Parental stressor scale: pediatric intensive care unit. Maternal Child Nursing Journal; 18: 187-198.

Miles MS, Carter MC, Hennessey J, Eberly TW, Riddle I. (1989). Testing a theoretical model: correlates of parental stress responses in the pediatric intensive care unit. Maternal Child Nursing Journal; 18: 207-219. 